\title{
Correction to: Unbound Plasma, Total Plasma and Whole-Blood Tacrolimus Pharmacokinetics Early After Thoracic Organ Transplantation
}

\author{
Maaike A. Sikma ${ }^{1,2}$ - Erik M. Van Maarseveen ${ }^{3}$. Claudine C. Hunault ${ }^{4}$. Javier M. Moreno ${ }^{5}$. Ed A. Van de Graaf ${ }^{6}$.

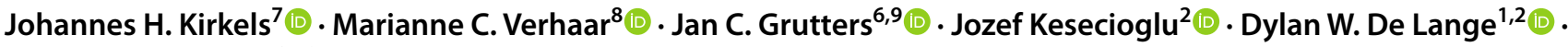 \\ Alwin D. R. Huitema ${ }^{3,10}$
}

Published online: 1 March 2022

(c) The Author(s) 2022

\section{Correction to: Clinical Pharmacokinetics (2020) 59:771-780 https://doi.org/10.1007/s40262-019-00854-1}

In this article the legend for Fig. 4 was inadvertently published as

"Simulations of different hematocrit values with a fixed whole-blood concentration of $9 \mathrm{ng} / \mathrm{mL}$. On the $y$-axis, the unbound tacrolimus plasma concentrations are plotted against haematocrit".

It should have been

"Simulations of different hematocrit values with a fixed whole-blood concentration of $10 \mathrm{ng} / \mathrm{mL}$. On the $y$-axis, the unbound tacrolimus plasma concentrations are plotted against haematocrit".
Open Access This article is licensed under a Creative Commons Attribution-NonCommercial 4.0 International License, which permits any non-commercial use, sharing, adaptation, distribution and reproduction in any medium or format, as long as you give appropriate credit to the original author(s) and the source, provide a link to the Creative Commons licence, and indicate if changes were made. The images or other third party material in this article are included in the article's Creative Commons licence, unless indicated otherwise in a credit line to the material. If material is not included in the article's Creative Commons licence and your intended use is not permitted by statutory regulation or exceeds the permitted use, you will need to obtain permission directly from the copyright holder. To view a copy of this licence, visit http://creativecommons.org/licenses/by-nc/4.0/.
The original article can be found online at https://doi.org/10.1007/ s40262-019-00854-1.

Maaike A. Sikma

m.a.sikma@umcutrecht.nl

1 Dutch Poisons Information Center and Department of Intensive Care, Division of Anesthesiology, Intensive Care and Emergency Medicine, University Medical Center Utrecht and Utrecht University, F06.149, P.O. Box 85500, 3508 GA Utrecht, The Netherlands

2 Department of Intensive Care, University Medical Center Utrecht and Utrecht University, Utrecht, The Netherlands

3 Department of Clinical Pharmacy, University Medical Center Utrecht and Utrecht University, Utrecht, The Netherlands

4 Dutch Poisons Information Center, University Medical Center Utrecht and Utrecht University, Utrecht, The Netherlands
5 Department of Pharmacy and Pharmaceutical Technology, University of Valencia and University Hospital Dr. Peset, Valencia, Spain

6 Department of Lung Transplantation, University Medical Center Utrecht and Utrecht University, Utrecht, The Netherlands

7 Department of Heart Transplantation, University Medical Center Utrecht and Utrecht University, Utrecht, The Netherlands

8 Department of Nephrology and Hypertension, University Medical Center Utrecht and Utrecht University, Utrecht, The Netherlands

9 Department of Pulmonology, St. Antonius Hospital, Nieuwegein, The Netherlands

10 Department of Pharmacy and Pharmacology, Netherlands Cancer Institute, Amsterdam, The Netherlands 